\title{
Omega-3 fatty acid levels and sensory quality of eggs following consumption of alpha-linolenic acid enriched diets
}

\author{
1, ${ }^{*}$ Kartikasari, L.R., ${ }^{2}$ Geier, M.S., ${ }^{2}$ Hughes, R.J., ${ }^{3}$ Bastian, S.E.P. and ${ }^{3}$ Gibson, R.A. \\ ${ }^{I}$ Department of Animal Science, Faculty of Agriculture, Universitas Sebelas Maret, Jl. Ir. Sutami No. \\ 36 A Surakarta 57126, Indonesia \\ ${ }^{2}$ School of Animal and Veterinary Sciences, The University of Adelaide, Roseworthy, SA 5371, Australia \\ ${ }^{3}$ School of Agriculture, Food and Wine, The University of Adelaide, Waite Campus, Urrbrae, SA 5064, \\ Australia
}

\section{Article history:}

Received: 7 December 2020

Received in revised form:

Accepted: 10 June 2021

Available Online: 20 June 2021

\section{Keywords:}

Laying hen,

Alpha-linolenic acid,

Eggs,

Omega-3 fats,

Sensory quality

DOI:

https://doi.org/10.26656/fr.2017.5(S2).010

\begin{abstract}
The aim of the study was to increase the levels of omega- 3 fatty acids in eggs, mainly in the form of eicosapentaenoic acid (EPA, 20:5n-3) and docosahexaenoic acid (DHA, 22:6n -3) as EPA and DHA have beneficial health effects. This study tested whether the inclusion of a vegetable source of omega-3 (n-3) fat in the form of alpha-linolenic acid (ALA, 18:3n-3) in the diets of laying hens (Hy-Line brown) would improve n-3 fat accumulation, without altering the product performance or the sensory characteristics of eggs. In this study, the ALA levels of the diets were varied from 0.3 to $6 \%$ energy (\%en). In order to optimize the conversion of ALA into n-3 long chain polyunsaturated fatty acids (LCPUFA), grain-based diets containing a low linoleic acid (LA, 18:2n-6) level were chosen as a basal diet, and the level of competing substrate, LA, in the dietary treatments was also kept constant. Results showed that increasing the levels of dietary ALA increased all n-3 LCPUFA (EPA, DPA, and DHA) in the eggs. Importantly, diets enriched with ALA did not impair the sensory quality of the eggs. In conclusion, brown laying hens fed ALA enriched diets produced eggs higher in $n-3$ fatty acids, and met the requirement needed for labelling as n-3 PUFA sources, which provides an alternative n-3 rich food for consumers.
\end{abstract}

\section{Introduction}

Foods rich in n-3 PUFA fatty acids are known to have health benefits for people. Therefore, health authorities recommend consuming n-3 fatty acids, especially eicosapentaenoic acid, EPA and docosahexaenoic acid, DHA (Thompson et al., 2019; Rao et al., 2020). The American Heart Association recommends that patients with documented coronary heart disease take approximately $1 \mathrm{~g} / \mathrm{d}$ EPA and DHA, preferably from oily fish although the supplementation of EPA and DHA could also be considered (Siscovick et al., 2017). However, because many people do not consume fish which is the main source of EPA and DHA in their daily diet, it is important to provide alternative foods rich in n-3 LCPUFA.

One of the efforts to improve the content of n-3 LCPUFA in the diet is by consuming eggs that contain high levels of omega- 3 fats. To produce eggs high in omega-3 fatty acids, layer hen diets can be supplemented with ingredients rich in omega-3 fatty acids sourced from the sea. This method is considered effective because of the direct incorporation of n-3 LCPUFA that was already contained in the source into the egg. The use of fish meal or fish oil in layer hen diet to produce n-3 eggs has been widely studied and resulted in an increase in $n-3$ LCPUFA, especially EPA and DHA (Gonzalez-Esquerra and Leeson, 2000a; Lawlor et al., 2010). For example, the inclusion of $60 \mathrm{~g} / \mathrm{kg}$ menhaden oil in laying hen diet resulted in eggs containing about 45-60 mg EPA/egg and 150-200 mg DHA/egg (Gonzalez-Esquerra and Leeson, 2000a). However, some investigators reported that there was a decrease in the organoleptic quality of the final product, such as a fishy odor and fishy off-flavor with the use of fish products in layer hen feed (Bou et al., 2005; Chekani-Azar, Shahriar, Maheri-Sis, 2008).

The use of omega-3 source ingredients from plants in layer hen feed can be seen as an alternative to increase n-3 PUFA. One of the plant sources rich in n-3 PUFA, ALA is flaxseed. Through this strategy, it is hoped that 
laying hens can convert ALA to DHA (Ahmad et al., $2012)$. The use of $10 \%$ flaxseed ( 33\% ALA) in the layer hen diet was reported to result in higher n-3 fatty acid deposition compared to the control group. It was further reported that the elevated levels of ALA and DHA in eggs increased by 8 and 2-fold, respectively (Bean and Leeson, 2003; Hayat et al., 2009). However, it was found that there was a higher level of ALA accumulation and lower accumulation of EPA and DHA with flaxseed-based feeding in layer hens compared to layer hens that were fed from sea sources, such as fish oil. Some studies have reported that feeding flaxseed up to the $10 \%$ level tends to limit the effectiveness of increasing the levels of n-3 fatty acids (Zuidhof et al., 2009; Al-Nasser et al., 2011). For example, Sari et al. (2002), found that there was no increase in the content of n-3 LCPUFA in eggs with the addition of 5, 10 and 15\% flaxseed in chicken feed. In addition, a diet high in LA can inhibit DHA production due to competition between ALA and LA for the use of the same enzyme in metabolic pathways. A study conducted by Kartikasari et al. (2010) proved that EPA and DHA levels in broiler tissue decreased with increasing LA levels in the feed while maintaining dietary ALA constant. In addition, eggs produced from hens fed diets containing $10 \%$ flaxseed led to differences in sensory attributes including aroma, taste, and off-flavor compared to control eggs (Hayat et al., 2010).

The use of ALA-rich vegetable oil in basal chicken feed against a background of low LA levels led to the significant accumulation of n-3 LCPUFA and total n-3 fatty acids (Kartikasari et al., 2012) without negatively affecting the sensory quality of chicken meat. There is little information regarding the use of ALA-rich vegetable oils in laying hens. Therefore, the aim of this study was to include the evaluation of the effectiveness of changes in dietary ALA levels while keeping LA constant at the incorporation of n-3 fatty acids and the sensory quality of eggs.

\section{Materials and methods}

\subsection{Ethical considerations}

Ethical approval for research activities was obtained from the Animal Ethics Committee of the South Australian Department of Primary Industry and the University of Adelaide. Research procedures followed and complied with the "Australian model code of practice for the welfare of animals: domestic poultry" (Standing Committee on Agriculture and Resource Management, 1995) and the "Australian code of practice for the care and use of animals for scientific purposes" (Australian Agriculture Council, 1997)

\subsection{Location}

Research activities were carried out at the Fatty Acid Laboratory and at the Sensory Evaluation Laboratory, Waite Campus, the University of Adelaide. The location for raising the chickens was at the Pig and Poultry Production Center (PPPI, SARDI), Roseworthy Campus, the University of Adelaide.

\subsection{Birds, management, and diets}

The experimental design of this research was a completely randomized block design using 8 replications for each ration. The dietary treatment was designed to maintain a constant LA level and increase the diet ALA level (\%en). Three experimental diets were provided for 24 Hy-Line brown laying hens. After the chickens have been weighed, each chicken was placed in one cage (500 $\mathrm{mm}$ width $\times 550 \mathrm{~mm}$ depth $\times 500 \mathrm{~mm}$ height). Eight cages were used as replications for each experimental diet. This diet was specially formulated for the layer hens used for this study (Ridley Agriproducts Pty Ltd, Murray Bridge, South Australia), which was designed to have low LA levels and varying levels of ALA. The treatment diets were prepared by incorporating a basal diet with pure or mixed vegetable oils. The ALA content of the treated feed was $0.3 \%$ (low ALA), $3 \%$ (moderate ALA) or $6 \%$ en (high ALA) while maintaining a constant LA level of around 4\%en (Table 1).

Table 1. Fatty acid composition of the experimental diets

\begin{tabular}{|c|c|c|c|}
\hline \multirow{3}{*}{ Diets } & \multicolumn{3}{|c|}{ Experimental diets } \\
\hline & 0.3 & 3 & 6 \\
\hline & (low ALA) & (moderate ALA) & (high ALA) \\
\hline Fat content $(\%)$ & 8.5 & 8.5 & 8.6 \\
\hline ALA (\%en) & 0.3 & 3.2 & 6.2 \\
\hline LA (\%en) & 2.3 & 4.4 & 4.4 \\
\hline LA:ALA ratio & 7.5 & 1.4 & 0.7 \\
\hline \multicolumn{4}{|l|}{ Fatty acids $(\%)^{1}$} \\
\hline Total SFA ${ }^{2}$ & 18.4 & 13.7 & 15.7 \\
\hline Total MUFA ${ }^{2}$ & 66.8 & 42.3 & 24.3 \\
\hline $18: 2 \mathrm{n}-6(\mathrm{LA})^{2}$ & 12.8 & 25.1 & 24.9 \\
\hline Total n-6 & 12.9 & 25.2 & 24.9 \\
\hline $18: 3 n-3(\mathrm{ALA})^{2}$ & 1.7 & 18.5 & 34.8 \\
\hline Total n-3 & 1.8 & 18.6 & 34.9 \\
\hline Total PUFA ${ }^{2}$ & 14.6 & 43.8 & 59.8 \\
\hline
\end{tabular}

${ }^{1}$ Values are presented as $\%$ of total fatty acids.

${ }^{2} \mathrm{SFA}=$ saturated fatty acid; MUFA = monounsaturated fatty acid; LA = linoleic acid; ALA = alpha- linolenic acid; PUFA = polyunsaturated fatty acid.

\subsection{Sample collection}

All eggs produced by each hen in the last 3 days of 
the 28 days of week 4 and week 12 were weighed individually. One egg from each laying hen was then cracked and the albumen and yolk were weighed separately and recorded. A total of 24 yolk samples on day 28 ( $\mathrm{n}=8$ egg yolks for each treatment) were stored at $-20^{\circ} \mathrm{C}$ to analyze the yolk fatty acid profile. Eggs produced at week 12 were collected for testing the consumer preference for boiled eggs.

\subsection{Lipid extraction and Fatty acid analysis}

The total fat (TL) was extracted from egg samples following the procedure of Folch et al. (1957) using a chloroform/methanol solution (2:1, v/v). Fatty acids methyl ester (FAME) was prepared following the method of Tu et al. (2010) using $1 \% \mathrm{H}_{2} \mathrm{SO}_{4}$ in methanol at $70^{\circ} \mathrm{C}$ for $3 \mathrm{hrs}$. The resulting FAME was extracted with n-heptane and then transferred to a vial gas chromatography (GC) containing anhydrous sodium sulfate. Methyl ester samples were stored at $-20^{\circ} \mathrm{C}$ for fatty acid analysis using GC, Hewlett-Packard $6890 \mathrm{GC}$ (CA, USA).

\subsection{Consumer acceptance of hard-boiled eggs}

The procedure for the study's consumer preference test was approved by the Human Ethics Committee of the University of Adelaide, Australia. After 12 weeks on the experimental diets, the eggs were collected and refrigerated $\left(4^{\circ} \mathrm{C}\right)$ for 15 days for easy peeling (Parpinello et al., 2000). A total of 20 brown eggs from each of the 3 dietary treatments and 20 commercial brown eggs were used for boiled egg consumer evaluation. To prepare boiled eggs, 20 eggs from each treatment were put into a stainless pot containing cold water. The eggs were brought to a boil using gas and simmered for eight minutes (Parpinello et al., 2000), then cooled in cold running water. The boiled eggs were then peeled and divided into four portions. One-quarter of an egg from each diet was placed in a plastic container coded with randomly three-digit numbers and covered. Before the egg samples were evaluated by consumers, the containers were kept warm in an oven at about $40^{\circ} \mathrm{C}$.

A group of consumers $(n=76)$ who had no allergies, liked and were willing to eat eggs, was recruited from both staff and students at the School of Agriculture, Food and Wine, the University of Adelaide. Before testing egg samples, consumers were asked to answer a questionnaire regarding their egg consumption behavior and demographic information. Panelists were then asked to rate their liking for the boiled egg samples by considering all characteristics including aroma and taste using a 9-point hedonic scale ranging from dislike extremely to like extremely (Wichchukit and O'Mahony, 2015). Consumer acceptance testing was conducted at the table in the open-plan cafeteria at the University of Adelaide's School of Agriculture, Food and Wine. The participants completed a questionnaire and rated their liking for the egg samples on the provided ballot papers. In order to clear the palate among the four samples, fresh water and fresh crackers were provided to each consumer.

\subsection{Statistical analysis}

The fatty acid composition data of the samples were analyzed by One-way ANOVA with a completely randomized design of three diets using eight replications using general analysis of variance on GenStat (Release 14). The experimental unit was a replicate consisting of eight adjacent birds which were fed as a group so that there were 8 cages for each diet and a total of 24 cages. The main effect of the diet ( 3 levels) was tested for the fatty acid profile of eggs, expressed as \% of total fatty acids and $\mathrm{mg} / \mathrm{yolk}$. If there are significant differences between treatments, then the analysis was continued with Tukey's multiple comparison test with a significance level set at $\mathrm{P}<0.05$. The consumer preference study was arranged in a completely randomized block design within two days of testing in which the individual assessors evaluated one egg sample. The data from the consumer acceptance study of boiled eggs were evaluated by One-way ANOVA in a randomized block design, with one block representing one assessor, using GenStat (Release 14). Attributes showing statistically significant differences were further analyzed using the Tukey test at the $95 \%$ confidence level, $\mathrm{P}<0.05$.

\section{Results and discussion}

\subsection{Fatty acids profiles of eggs}

The fatty acid composition of eggs produced on day 28 of each dietary intervention was evaluated (Table 2). The use of plant oils rich in ALA content in the laying hens' feeds significantly increased all n-3 LCPUFA (EPA, DPA, and DHA), total n-3 PUFA, and total PUFA content. The EPA content of chicken eggs fed a diet containing $0.3,3$, and $6 \%$ en ALA were 0.0, 0.1, and $0.2 \%$ of the total fatty acids, respectively. The DPA content of eggs increased $(\mathrm{P}<0.001)$ to about 4 times higher with the enrichment of layer hens' feed with ALA compared to those not supplemented with ALA. The increase in total $n-3$ is at the expense of monounsaturated fatty acids (MUFA) accumulation. Importantly, the feed enriched with ALA levels did not cause a difference in the saturated fatty acid (SFA) content of eggs while the polyunsaturated fatty acids (PUFA) content significantly increased by about 2.5 times.

The results presented in this study indicate a major change in the fatty acid profile of egg yolks by the ALA 
Table 2. Fatty acid profiles of eggs produced at day 28 of dietary intervention ${ }^{1}$

\begin{tabular}{|c|c|c|c|c|c|}
\hline \multirow[b]{2}{*}{ ALA Level (\%en) } & \multicolumn{3}{|c|}{ Experimental diets } & \multirow[b]{2}{*}{ P-Value } & \multirow[b]{2}{*}{ Significance $^{2}$} \\
\hline & $\begin{array}{c}0.3 \\
\text { (low) }\end{array}$ & $\begin{array}{c}3 \\
\text { (moderate) } \\
\end{array}$ & $\begin{array}{c}6 \\
\text { (high) } \\
\end{array}$ & & \\
\hline \multicolumn{6}{|l|}{ Fatty acids $(\%)^{3}$} \\
\hline $16: 0$ & 20.12 & 20.14 & 20.18 & 0.99 & NS \\
\hline 18:0 & $7.16^{\mathrm{b}}$ & $7.68^{\mathrm{b}}$ & $8.52^{\mathrm{a}}$ & 0.001 & $* *$ \\
\hline Total SFA & 27.87 & 28.21 & 29.05 & 0.108 & NS \\
\hline $16: 1 n-7$ & $4.91^{\mathrm{a}}$ & $2.09^{\mathrm{b}}$ & $2.24^{\mathrm{b}}$ & 0.001 & $* *$ \\
\hline $18: 1 n-9$ & $50.19^{\mathrm{a}}$ & $43.94^{\mathrm{b}}$ & $39.06^{\mathrm{c}}$ & 0.001 & $* *$ \\
\hline $18: 1 n-7$ & $4.36^{\mathrm{a}}$ & $2.19^{\mathrm{b}}$ & $1.70^{\mathrm{c}}$ & 0.001 & $* *$ \\
\hline Total MUFA & $61.27^{\mathrm{a}}$ & $49.96^{\mathrm{b}}$ & $44.22^{\mathrm{c}}$ & 0.001 & $* *$ \\
\hline Total n-9 & $52.04^{\mathrm{a}}$ & $45.53^{b}$ & $40.17^{\mathrm{c}}$ & 0.001 & $* *$ \\
\hline Total n-7 & $9.27^{\mathrm{a}}$ & $4.29^{b}$ & $3.94^{\mathrm{b}}$ & 0.001 & $* *$ \\
\hline $18: 2 n-6(L A)$ & $6.82^{\mathrm{b}}$ & $12.81^{\mathrm{a}}$ & $13.33^{\mathrm{a}}$ & 0.001 & $* *$ \\
\hline $18: 3 n-6$ & $0.00^{\mathrm{c}}$ & $0.09^{\mathrm{a}}$ & $0.06^{\mathrm{b}}$ & 0.001 & $* *$ \\
\hline $20: 3 n-6$ & $0.16^{\mathrm{a}}$ & $0.11^{\mathrm{b}}$ & $0.09^{b}$ & 0.001 & $* *$ \\
\hline $20: 4 n-6$ (AA) & $1.61^{\mathrm{a}}$ & $1.09^{\mathrm{b}}$ & $0.78^{\mathrm{c}}$ & 0.001 & $* *$ \\
\hline Total n-6 & $9.12^{b}$ & $14.30^{\mathrm{a}}$ & $14.33^{\mathrm{a}}$ & 0.001 & $* *$ \\
\hline \multicolumn{6}{|l|}{$(\mathrm{ALA})$} \\
\hline $18: 3 n-3$ & $0.24^{\mathrm{c}}$ & $4.45^{b}$ & $9.54^{\mathrm{a}}$ & 0.001 & $* *$ \\
\hline $20: 3 n-3$ & $0.00^{\mathrm{c}}$ & $0.08^{\mathrm{b}}$ & $0.14^{\mathrm{a}}$ & 0.001 & $* *$ \\
\hline \multicolumn{6}{|l|}{ (EPA) } \\
\hline $20: 5 n-3$ & $0.00^{\mathrm{c}}$ & $0.11^{\mathrm{b}}$ & $0.18^{\mathrm{a}}$ & 0.001 & $* *$ \\
\hline \multicolumn{6}{|l|}{ (DPA) } \\
\hline $22: 5 n-3$ & $0.12^{b}$ & $0.38^{\mathrm{a}}$ & $0.43^{\mathrm{a}}$ & 0.001 & $* *$ \\
\hline \multicolumn{6}{|l|}{$\overline{(\mathrm{DHA})}$} \\
\hline $22: 6 n-3$ & $0.89^{c}$ & $2.21^{\mathrm{a}}$ & $1.93^{b}$ & 0.001 & $* *$ \\
\hline Total n-3 & $1.35^{\mathrm{c}}$ & $7.32^{b}$ & $12.22 \mathrm{a}$ & 0.001 & $* *$ \\
\hline Total PUFA & $10.47^{\mathrm{c}}$ & $21.63^{\mathrm{b}}$ & $26.56^{\mathrm{a}}$ & 0.001 & $* *$ \\
\hline n-3 LCPUFA & $1.01^{\mathrm{b}}$ & $2.71^{\mathrm{a}}$ & $2.54^{\mathrm{a}}$ & 0.001 & $* *$ \\
\hline LA:ALA ratio & $28.24^{\mathrm{a}}$ & $2.88^{\mathrm{b}}$ & $1.41^{\mathrm{b}}$ & 0.001 & $* *$ \\
\hline $\mathrm{n} 6: \mathrm{n} 3$ & $6.77^{\mathrm{a}}$ & $1.95^{\mathrm{b}}$ & $1.18^{\mathrm{c}}$ & 0.001 & $* *$ \\
\hline
\end{tabular}

${ }^{1}$ Values are means of eight observations per treatment. Values in the same row with no common superscript are significantly different $(\mathrm{P}<0.05)$.

$2 * * \mathrm{P}<0.01 ; \mathrm{NS}$, not significant.

${ }^{3}$ SFA, saturated fatty acid; MUFA, monounsaturated fatty acid; LA, linoleic acid; AA, arachidonic acid, ALA, alpha-linolenic acid; EPA, eicosapentaenoic acid; DPA, docosapentaenoic acid; DHA, docosahexaenoic acid; PUFA, polyunsaturated fatty acid.

enriched feed, which can be summarized as an increase in PUFA levels and a decrease in MUFA. This clearly shows that there is a direct relationship between feed ALA levels and the n-3 content of eggs, especially accumulated as ALA and n-3 LCPUFAs. These results confirm the established idea that the composition of the $n$ -3 fatty acids in dietary fat is directly responsible for the type of fatty acid content in egg yolk and that modifying the fatty acid composition of the diet can manipulate the fatty acid profile of the egg yolk (Neijat et al., 2016). An increase in egg n-3 LCPUFA content when high ALA levels were included in the diet indicated that laying hens have the ability to desaturate and elongate alphalinolenic acid to n-3 LCPUFA in eggs. However, it appears that there is a limited conversion of ALA to n-3
LCPUFA (Zhang et al., 2017) and in particular, the capacity of layer hens to convert ALA to DHA (Ehr et al., 2017). The findings of this study indicated that egg DHA accumulation was higher $(\mathrm{P}<0.001)$ in eggs produced from laying hens fed with ALA levels of 3 and $6 \%$ en compared to those fed with low ALA $(0.3 \%$ en). However, we observed that the highest egg DHA levels were achieved when chickens were fed at the 3\%en ALA level. The increase in DHA content of eggs from chickens that were fed with the addition of 3 and $6 \%$ en ALA was 2.5 and 2.2 times, respectively. The deposition of EPA $(0.2 \%)$ and DPA $(0.4 \%)$ in eggs observed in this experiment was relatively low, which may be due to the limited ability to accumulate EPA and DPA in egg fat. This finding is as reported by Gonzalez-Esquerra and 
Leeson (2000b) where the levels of EPA, DPA and DHA from chicken eggs fed a diet supplemented with $2 \%$ menhaden oil containing 3.9\% EPA, $1 \%$ DPA, and $1,4 \%$ DHA were $0.3,0.2$, and $1.7 \%$, respectively. These results correspond to the amount of DHA in eggs, $87 \mathrm{mg} / \mathrm{egg}$, identical to the levels found in egg laying hens that were fed 3\%en ALA. This suggests that vegetable oil rich in ALA (n-3 PUFA) added to feed against a background of low LA levels can lead to a significant accumulation of $n$ -3 LCPUFA levels in eggs.

In this study, the accumulation of DHA gradually doubled with the use of layer hen feeds enriched with 3 and $6 \%$ en ALA. There appears to be a maximal ALA level for conversion to DHA. Layers fed 3\%en ALA produced the highest amount of DHA (2.2\%); however, when the dietary ALA level exceeds $3 \%$ en, there was no further increase in the DHA level. These findings are consistent with reports that a diet enriched with high levels of PUFAs, including ALA and LA, can inhibit DHA production (Gibson et al., 2013). In addition, no positive response in egg DHA synthesis with increased feed ALA levels could be explained as a result of competition between 18-carbon PUFA, LA and ALA, in the use of $\Delta$-desaturase enzymes in the synthetic pathway (Gibson et al., 2011; Gibson et al., 2013). Competition in utilizing the same desaturase and elongase enzymes between LA and ALA for bioconversion to n-3 LCPUFA is well known (Barceló-Coblijn and Murphy, 2009; Nain et al., 2012). This is as reported by Kartikasari et al. (2010) where the accumulation of n-3 LCPUFA in chicken tissue was reduced with an increase in the amount of LA in the feed; however, n-3 LCPUFA levels (EPA and DHA) enhanced by increasing the levels of dietary ALA while holding dietary LA in a low level (Kartikasari et al., 2012). These findings are consistent with previous studies which found that increased feed ALA could achieve the maximum attainable DHA level (Sari et al., 2002). For example, a study conducted by Grobas et al. (2001) found that the DHA content of eggs did not change with flaxseed oil supplementation from 5 to $10 \%$, which is consistent with the observations of the current study.

The fatty acid composition of eggs expressed in $\mathrm{mg} /$ egg yolk was also evaluated in this study (Table 3). ALA, n-3 LCPUFA, total n-3 in egg yolk were accumulated more with ALA-enriched feed, while the evaluation of AA levels showed a decrease. The increase in ALA, EPA, DPA and total n-3 occurred linearly $(\mathrm{P}<0.01)$. However, the analysis showed that the highest DHA levels (87 mg/egg yolk) were found in laying hens

Table 3. Fatty acid profiles of eggs produced at day 84 of dietary intervention expressed in mg/yolk or egg ${ }^{1}$

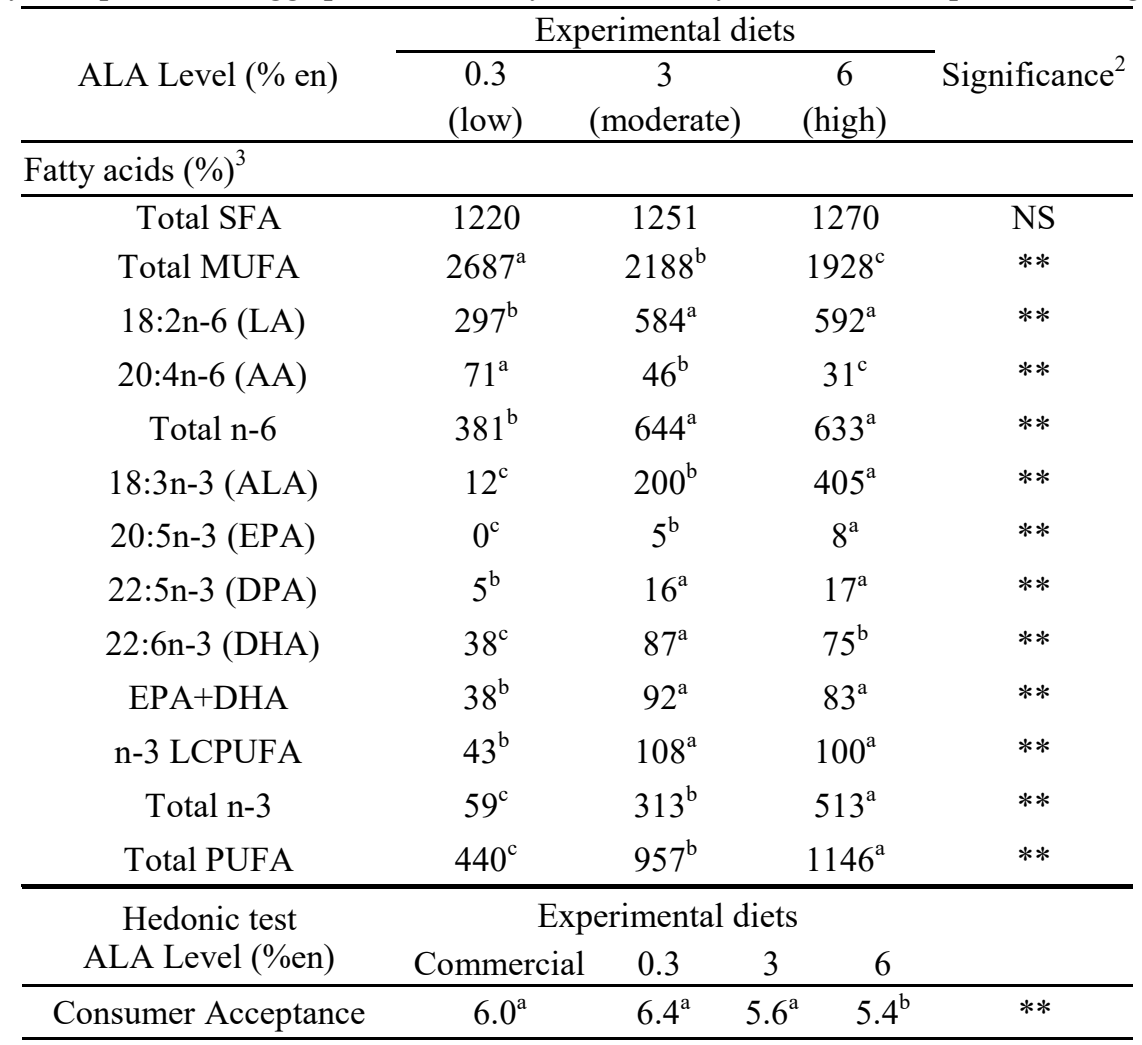

${ }^{1}$ Values are means of eight observations per treatment. Values in the same row with no common superscripts are significantly different $(\mathrm{P}<0.05)$.

$2 * \mathrm{P}<0.05 ; * * \mathrm{P}<0.01 ; \mathrm{NS}$, not significant.

${ }^{3}$ SFA, saturated fatty acid; MUFA, monounsaturated fatty acid; LA, linoleic acid; AA, arachidonic acid, ALA, alpha-linolenic acid; EPA, eicosapentaenoic acid; DPA, docosapentaenoic acid; DHA, docosahexaenoic acid; PUFA, polyunsaturated fatty acid. 
that were fed with ALA content of $3 \% \mathrm{en}$, indicating that the DHA levels in eggs had reached the maximum level. The feed containing the highest ALA (6\%en) increased the EPA, DPA and DHA content of eggs by about 8,3 and 2 times, respectively. The use of moderate $(3 \% \mathrm{en})$ and high $(6 \%$ en) ALA led to an increase in total n-3 to 313 and $513 \mathrm{mg} /$ yolk (Table 3), respectively. This suggests that chickens fed moderate and high ALA enriched diets can produce eggs that achieve the minimum requirements needed for egg labeling as a source of n-3 PUFA (300 mg/egg) (Nain et al., 2012).

\subsection{Consumer acceptance of hard-boiled eggs}

The consumers in this study $(\mathrm{n}=76)$ were between 19 and 65 years old and were gender-balanced. About $70 \%$ of consumers with tertiary qualifications and $74 \%$ had no formal food science or consumer education or training. The majority were students $(65 \%)$ and $80 \%$ of all consumers had no experience in the food industry. Almost all consumers (96\%) consumed boiled eggs and $70 \%$ reported consuming boiled eggs at least once a month. No consumer reported having an egg allergy. Importantly, the evaluation of consumer acceptance of boiled eggs showed that based on taste and flavor there was no difference in consumer preferences between commercial eggs purchased from local supermarkets and eggs from chickens fed a diet enriched with up to $3 \%$ en ALA. The score average of the evaluation was 6 which indicates a "like slightly" rating (Table 3). It appears that eggs produced from hens fed dietary treatments with the addition of $6 \%$ en ALA levels were significantly less liked than all other eggs; however, all the eggs were acceptable. This finding was in agreement with the results of previous investigators (Hayat et al., 2010).

\section{Conclusion}

The findings of this study suggest that the diet enriched with 3\%en ALA was found to be optimum with respect to n-3 fatty acid accumulation and the consumer acceptance of the boiled eggs; however, ALA can be added to commercial laying hen feed up to $6 \%$ en ALA and increase all n-3 fats. Eggs from hens fed both the moderate $(3 \%$ en $)$ and high $(6 \%$ en $)$ levels of ALA reached $300 \mathrm{mg}$ of total n-3 PUFA/egg, which is the minimum content needed for labelling the eggs as an n-3 PUFA source. Importantly, the dietary inclusion of ALA assessed did not alter the consumer acceptance of the boiled eggs compared to the commercial eggs. The findings of this study indicate that vegetable oils could be an alternative ALA source to marine sources. As laying hens fed moderate and high ALA diets resulted in eggs higher in n-3 LCPUFA without influencing consumer acceptance of the eggs, this provides an alternative food rich in n-3 PUFA for consumers and may help approach the recommended intake for human health.

\section{Conflict of interest}

The authors declare no conflict of interest.

\section{Acknowledgments}

The authors would like to thank Dr. John Carragher for his suggestions and constructive comments and the technical support staff at the SARDI Pig and Poultry Production Institute (PPPI), Roseworthy Campus for help in conducting the animal experiments. We thank Ms. Ela Zielinski for the technical assistance and advice in the fatty acid analysis. We acknowledge the financial support from the Directorate General of Higher Education, Ministry of National Education Indonesia, the University of Adelaide, and the South Australian Department of Further Education, Employment, Science and Technology, Australia.

\section{References}

Ahmad, S., Ahsan-ul-Haqb, Yousaf, M., Sabria, M.A. and Kamrana, Z. (2012). Response of laying hens to omega-3 fatty acids for performance and egg quality. Avian Biology Research, 5(1), 1-10. https:// doi.org/10.3184/175815512X13291506128070

Al-Nasser, A.Y., Al-Saffar, A.E., Abdullah, F.K., AlBahouh, M.E., Ragheb, G. and Mashaly, M.M. (2011). effect of adding flaxseed in the diet of laying hens on both production of omega- 3 enriched eggs and on production performance. International Journal of Poultry Science, 10(10), 825-831. https:// doi.org/10.3923/ijps.2011.825.831

Barceló-Coblijn, G. and Murphy, E.J. (2009). Alphalinolenic acid and its conversion to longer chain $n-3$ fatty acids: Benefits for human health and a role in maintaining tissue n-3 fatty acid levels. Progress in Lipid Research, 48(6), 355-374. https:// doi.org/10.1016/j.plipres.2009.07.002

Bean, L.D. and Leeson, S. (2003). Long-term effects of feeding flaxseed on performance and egg fatty acid composition of brown and white hens. Poultry Science, 82(3), 88-394. https://doi.org/10.1093/ $\mathrm{ps} / 82.3 .388$

Bou, R., Guardiola, F., Barroeta, A.C. and Codony, R. (2005). Effect of dietary fat sources and zinc and selenium supplements on the composition and consumer acceptability of chicken meat. Poultry Science, 84(7), 1129-1140. https://doi.org/10.1093/ ps/84.7.1129

Chekani-Azar, A., Shahriar, H.A. and Maheri-Sis, N. 
(2008). Omega-3 fatty acids enrichment and organoleptic charateristic of broiler meat. Asian Journal of Animal and Veterinary Advances, 3(2), 62 -69. https://doi.org/10.3923/ajava.2008.62.69

Ehr, I.J., Persia, M.E. and Bobeck, E.A. (2017). Comparative omega-3 fatty acid enrichment of egg yolks from first-cycle laying hens fed flaxseed oil or ground flaxseed. Poultry Science, 96(6), 1791-1799. https://doi.org/10.3382/ps/pew462

Folch, J., Lees, M. and Sloane Stanley, G.H. (1957). A simple method for the isolation and purification of total lipids from animal tissues. Journal of Biological Chemistry, 226(1), 497-509. https:// doi.org/10.1016/S0021-9258(18)64849-5

Gibson, R.A., Muhlhausler, B. and Makrides, M. (2011). Conversion of linoleic acid and alpha-linolenic acid to long-chain polyunsaturated fatty acids (LCPUFAs), with a focus on pregnancy, lactation and the first 2 years of life. Maternal and Child Nutrition, 7(Suppl. 2), 17-26. https:// doi.org/10.1111/j.1740-8709.2011.00299.x

Gibson, R.A., Neumann, M.A., Lien, E.L., Boyd, K.A. and Tu, W.C. (2013). Docosahexaenoic acid synthesis from alpha-linolenic acid is inhibited by diets high in polyunsaturated fatty acids. Prostaglandins, leukotrienes, and essential fatty acids, 88(1), 139-146. https://doi.org/10.1016/ j.plefa.2012.04.003

Gonzalez-Esquerra, R. and Leeson, S. (2000a). Effects of menhaden oil and flaxseed in broiler diets on sensory quality and lipid composition of poultry meat. British Poultry Science, 41(4), 481-488. https:// doi.org/10.1080/713654967

Gonzalez-Esquerra, R. and Leeson, S. (2000b). Effect of feeding hens regular or deodorized menhaden oil on production parameters, yolk fatty acid profile, and sensory quality of eggs. Poultry Science, 79(11), 1597-1602. https://doi.org/10.1093/ps/79.11.1597

Grobas, S., Mendez, J., Lazaro, R., de Blas, C. and Mateo, G.G. (2001). Influence of source and percentage of fat added to diet on performance and fatty acid composition of egg yolks of two strains of laying hens. Poultry Science, 80(8), 1171-1179. https://doi.org/10.1093/ps/80.8.1171

Hayat, Z., Cherian, G., Pasha, T.N., Khattak, F.M. and Jabbar, M.A. (2009). Effect of feeding flax and two types of antioxidants on egg production, egg quality, and lipid composition of eggs. Journal of Applied Poultry Research, 18(3), 541-551. https:// doi.org/10.3382/japr.2009-00008

Hayat, Z., Cherian, G., Pasha, T.N., Khattak, F.M. and Jabbar, M.A. (2010). Sensory evaluation and consumer acceptance of eggs from hens fed flaxseed and 2 different antioxidants. Poultry Science, 89(10), 2293-2298. https://doi.org/10.3382/ps.2009-00575

Kartikasari, L.R., Hughes, R.J., Geier, M.S., Makrides, M. and Gibson, R.A. (2010). Diets high in linoleic acid reduce omega-3 long chain polyunsaturated fatty acids in chicken tissues, presented at $21^{\text {st }}$ Annual Australian Poultry Science Symposium, Sydney, 2010. Sydney NSW: University of Sydney.

Kartikasari, L.R., Hughes, R.J., Geier, M.S., Makrides, M. and Gibson, R.A. (2012). Dietary alpha-linolenic acid enhances omega-3 long chain polyunsaturated fatty acid levels in chicken tissues. Prostaglandins, leukotrienes, and essential fatty acids, 87(4-5), 103109. https://doi.org/10.1016/j.plefa.2012.07.005

Lawlor, J.B., Gaudette, N., Dickson, T. and House, J.D. (2010). Fatty acid profile and sensory characteristics of table eggs from laying hens fed diets containing microencapsulated fish oil. Animal Feed Science and Technology, 156(3-4), 97-103. https:// doi.org/10.1016/j.anifeedsci.2010.01.003

Nain, S., Renema, R.A., Korver, D.R. and Zuidhof, M.J. (2012). Characterization of the n-3 polyunsaturated fatty acid enrichment in laying hens fed an extruded flax enrichment source. Poultry Science, 91(7), 1720 -1732. https://doi.org/10.3382/ps.2011-02048

Neijat, M., Ojekudo, O. and House, J.D. (2016). Effect of flaxseed oil and microalgae DHA on the Production performance, fatty acids and total lipids of egg yolk and plasma in laying hens. Prostaglandins, leukotrienes, and Essential Fatty Acids, 115, 77-88. https://doi.org/10.1016/ j.plefa.2016.10.010

Parpinello, G.P., Meluzzi, A., Sirri, F., Tallarico, N. and Versari, A. (2006). Sensory evaluation of egg products and eggs laid from hens fed diets with different fatty acid composition and supplemented with antioxidants. Food Research International, 39 (1), 47-52. https://doi.org/10.1016/ j.foodres.2005.05.010

Rao, A. Briskey, D., Nalley, J.O. and Ganuza, E. (2020). Omega-3 eicosapentaenoic acid (EPA) rich extract from the microalga nanochloropsis decreases cholesterol in healthy individuals: a double-blind, randomized, placebo-controlled, three-month supplementation study. Nutrients, 12(6), 1869. https://doi.org/10.3390/nu12061869

Sari, M., Aksit, M., Ozdogan, M. and Basmacioglu, H. (2002). Effects of addition of flaxseed to diets of laying hens on some production characteristics, levels of yolk and serum cholesterol, and fatty acid compositions of yolk. Archiv fur Geflugelkunde, 66 (2), 75-79. 
Siscovick, D.S., Barringer, T.A., Fretts, A.M., Wu, JHY., Lichtenstein, A.H., Costello, R.B., Kris-Etherton, P.M., Jacobson, T.A., Engler, M.B., Alger, H.M., Appel, L.J. and Mozaffarian, D. (2017). Omega-3 polyunsaturated fatty acid (fish oil) supplementation and the prevention of clinical cardiovascular disease, 135(15), e867-e884. https://doi.org/10.1161/ CIR.0000000000000482

Thompson, M., Hein, N., Hanson, C., Smith, L.M., Anderson-Berry, A., Richter, C.K., Bisselou, K.S., Appiah, K.A., Kris-Etherton, P., Skulas-Ray, A.C. and Nordgren, T.M. (2019). Omega-3 fatty acid intake by age, gender, and pregnancy status in the United States: National Health and Nutrition Examination Survey 2003-2014. Nutrients, 11(77), 1 -14. https://doi.org/10.3390/nu11010177

Tu, W.C., Cook-Johnson, R.J., James, M.J., Muhlhausler, B.S. and Gibson, R.A. (2010). Omega3 long chain fatty acid synthesis is regulated more by substrate levels than gene expression. Prostaglandins, leukotrienes, and Essential Fatty Acids, 83(2), 61-68. https://doi.org/10.1016/ j.plefa.2010.04.001

Wichchukit, S. and O'Mahony, M. (2015). The 9-point hedonic scale and hedonic ranking in food science: some reappraisals and alternatives. Journal of the Science of Food and Agriculture, 95(11), 2167-2178. https://doi.org/10.1002/jsfa.6993

Zhang, P., Tang, C., Ding, Z., Huang, H. and Sun, Y. (2017). Effects of simultaneous supplementation of laying hens with $\alpha$-linolenic acid and eicosapentaenoic acid/docosahexaenoic acid resources on egg quality and n-3 fatty acid profile. Asian-Australasian Journal of Animal Sciences, 30 (7), 973-978. https://doi.org/10.5713/ajas.15.0850

Zuidhof, M.J., Betti, M., Korver, D.R., Hernandez, F.I.L., Schneider, B.L., Carney, V.L. and Renema, R.A. (2009). Omega-3-enriched broiler meat: 1. Optimization of a production system. Poultry Science, 88(5), 1108-1120. https://doi.org/10.3382/ ps.2008-00171 